\title{
Modeling and Rotor Current Control of Doubly-fed Induction Machine with Complex Signal Flow Graphs
}

\author{
A. M. Khambadkone, Rajib Datta and V. T. Ranganathan \\ Indian Institute of Science, \\ Bangalore 560 012, India.
}

\begin{abstract}
Doubly fed induction machine can be used for wind energy generation. The control of rotor currents can facilitate variable speed constant frequency operation at unity power factor. A model based on complex signal flow graph is developed. This leads to a physically insightful control structure of the machine. A rotor current control strategy based on the complex signal flow graph is developed to facilitate fast current control. The paper gives the analysis, design and simulation for rotor current control in doubly fed induction machine.
\end{abstract}

\section{INTRODUCTION}

Doubly fed induction machine have often been used in high power applications where the speed control range is limited. Since the control is carried out on the rotor side the power ratings of the controller can be small. The stator is directly connected to the constant frequency supply mains. When the rotor current is controlled such that a variation in slip is possible the angular velocity of the rotor can be changed. This structure is especially useful in wind-energy generators. The wound rotor induction machine is doubly fed to allow for variable speed constant frequency operation. In addition the rotor current control with respect to stator field coordinate system allows for reactive power control and unity power factor operation. In this paper we discuss the modeling of a doubly fed induction machine using complex signal flow graphs, on the basis of which a rotor current control methodology is given. As against the conventional method in which a PI-controller is used or a state variable control using modern control theory is implemented we propose an intuitive approch to controller design based on the complex signal flow graph. Simulation results of the scheme are presented.

\section{Dynamic Structure of Doubly fed InDUCTION MACHINE USING COMPLEX Signal Flow GraphS}

In recent past Holtz [1] has shown that a complex space vector representation can explain the under lying physical phenomena in dynamic behavior of induction machines. Electromagnetic quantities cannot be interpreted as two phase machine quantities as this leads to erroneous interpretation of the system behavior. By describing the $\mathrm{AC}$ winding as a complex space vector system it is possible to attribute complex roots to the system. The eigen behavior of the complex roots have to be interpreted in terms of complex space vectors. Hence the state variables of the machine will be expressed in terms of complex space vectors. A complex space vector is a vector describing the sinusoidal distribution of the electromagnetic quantity in a rotating field machine. It is directed along the peak of the sinusoid and has a magnitude proportional to the peak of the sinusoid.

To model the doubly fed induction machine we can express the stator and rotor voltage equation in field coordinates as

$$
\begin{aligned}
& \boldsymbol{u}_{\mathrm{s}}=r_{\mathrm{s}} i_{\mathrm{s}}+\frac{d \psi_{\mathrm{s}}}{d \tau}+j \omega_{\mathrm{s}} \psi_{\mathrm{s}} \\
& \boldsymbol{u}_{\mathrm{r}}=r_{\mathrm{r}} i_{\mathrm{r}}+\frac{d \psi_{\mathrm{r}}}{d \tau}+j\left(\omega_{\mathrm{s}}-\omega\right) \psi_{\mathrm{r}}
\end{aligned}
$$

In case of the doubly fed induction machine the control is exercised on the rotor side. The rotor current is the state variable which will be controlled. Since the stator frequency is constant any change in the magnetization of the machine caused due to the change in the rotor current will cause a change in the stator voltage. However, if the induction machine is used as a variable speed constant frequency generator for wind energy application the stator will be connected to the grid. Hence the stator voltage and frequency will have to be constant. If we choose the stator flux linkage vector as the other state variable, we are able to satisfy the above condition and achieve a constant stator flux. Moreover, by choosing a coordinate system oriented along the stator flux vector decoupling of the rotor current vector is possible. By controlling the direct and quadrature component of the rotor current both reactive and active power control can be achieved. In order to implement a vector control scheme we will develop the system model in terms of stator flux and rotor current space vectors. By eliminating the stator current and the rotor flux from (1) and (2) we get the following in state-space form

$$
\dot{x}=A x+B u
$$




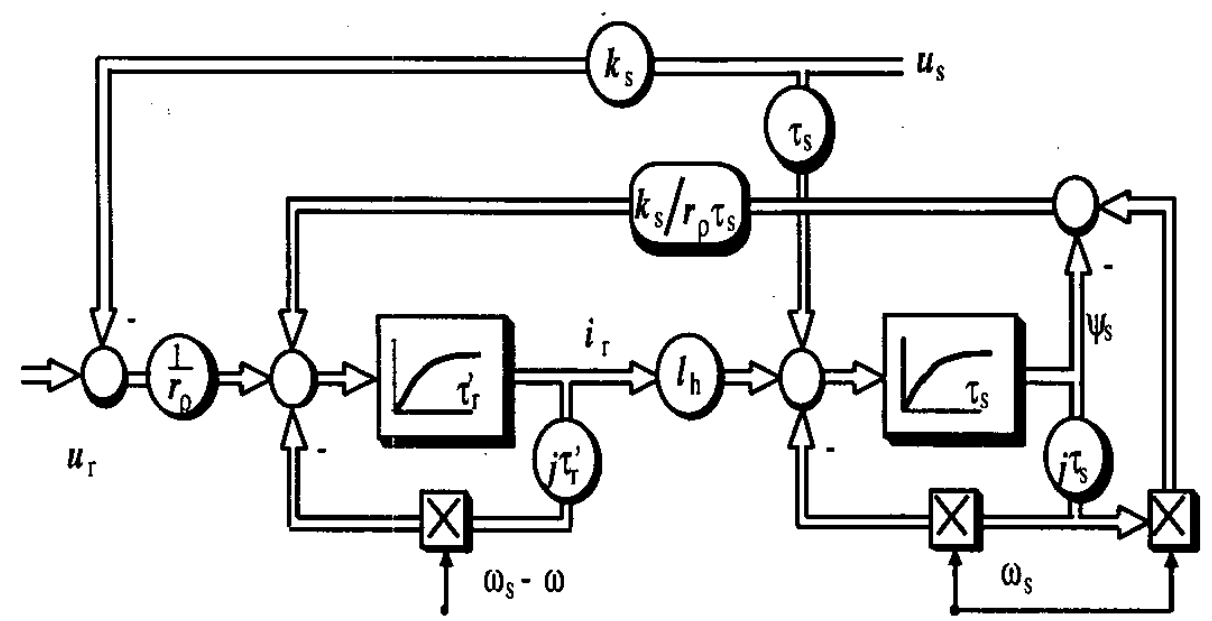

Fig. 1. Signal flow graph of the electromagnetic system of the induction machine

with

$$
\begin{gathered}
A=\left[\begin{array}{lr}
-\frac{1}{\tau_{\mathrm{r}}^{\prime}}-j\left(\omega_{\mathrm{s}}-\omega\right) & \frac{k_{\mathrm{o}}}{r_{\rho} \tau_{\mathrm{r}}^{\prime}}\left(\frac{1}{\tau_{\mathrm{s}}}+j \omega\right) \\
\frac{l_{\mathrm{h}}}{\tau_{\mathrm{a}}} & -\left(\frac{1}{\tau_{\mathrm{s}}}+j \omega_{\mathrm{s}}\right)
\end{array}\right] \\
x=\left[\begin{array}{c}
i_{\mathrm{r}} \\
\psi_{\mathrm{s}}
\end{array}\right] \\
B=\left[\begin{array}{cr}
\frac{1}{\sigma l_{\mathrm{r}}} & -\frac{k_{\mathrm{s}}}{\sigma l_{\mathrm{r}}} \\
0 & 1
\end{array}\right]
\end{gathered}
$$

and

$$
u=\left[\begin{array}{l}
u_{\mathrm{r}} \\
u_{\mathrm{s}}
\end{array}\right]
$$

where $\tau_{\mathrm{r}}^{\prime}=\sigma l_{\mathrm{r}} / r_{\rho}, \tau_{\mathrm{s}}=l_{\mathrm{s}} / r_{\mathrm{s}}, k_{\mathrm{s}}=l_{\mathrm{h}} / l_{\mathrm{s}}$ and $r_{\rho}=r_{\mathrm{r}}+\left(l_{\mathrm{h}} / l_{\mathrm{s}}\right)^{2} r_{\mathrm{s}}$. The total leakage factor is $\sigma=1-l_{\mathrm{h}}^{2} / l_{\mathrm{s}} l_{\mathrm{r}}$. The complex signal flow diagram of the electromagnetic system is shown in Fig. 1. The

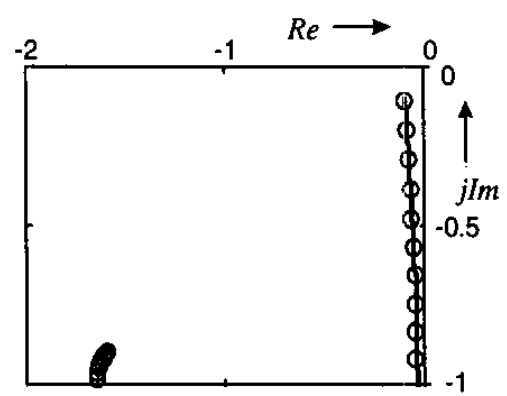

Fig. 2. Pole plot of the electromagnetic system of the machine

poles of the machine will vary with angular velocity. Solving the system matrix for a constant supply frequency and varying angular frequency we obtain the pole position as in Fig. 2. It can be seen that the pole plot is similar to the stator fed induction machine; only that the relative freqency of observation is different. In fact the signal flow graph is a mirror image of the stator fed machine only that . an additional voltage input also exists.

\section{A. Stator Flux oriented Vector Control}

In doubly-fed induction machine the stator can be connected to the constant frequency constant voltage source. The rotor current is then used to control both the active and reactive power on the stator side. In order to decouple the rotor current component into the active and reactive part we will orient the coordinate reference frame along the stator flux vector. In so doing the rotor current can be split into the reactive current component $i_{\text {rd }}$ and the active current component $i_{\text {rq }}$. In order to achieve unity power factor operation a fast current vector control is necessary. Leonhard [2] has thus simplified the model of the doubly fed machine assuming a fast current control. We will show how a fast current control is able to simplify the model. Moreover, we will discuss how this current control is to be designed considering the non-linear behavior of the machine.

\section{MODELING AND STATE FEEDBACK LINEARIZATION OF A DOUBLY FED INDUCTION MACHINE}

A doubly fed induction generator can be used in wind energy based power plants. The active power flow into the grid is controlled by injecting the appropriate value of the rotor current in quadrature with the stator flux. The power factor on the stator side can be controlled by injecting the required value of rotor current in phase with the stator flux. 


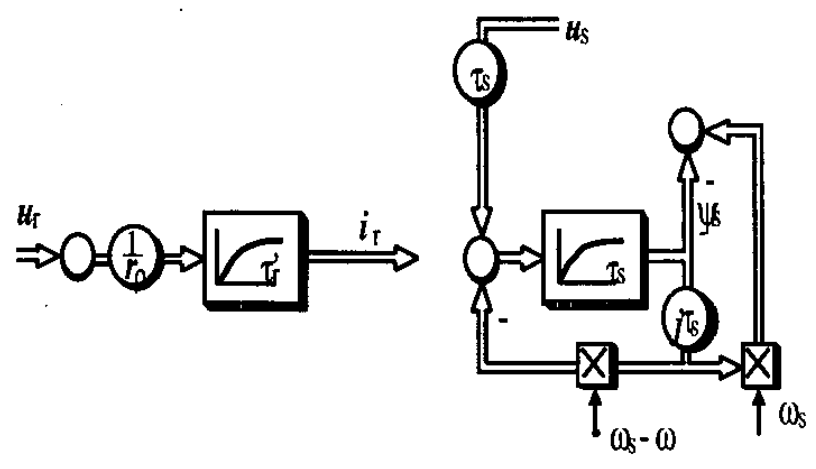

Fig. 3. Signal flow graph of the electromagnetic system of the induction machine after state feedback

However, for all the operating conditions the stator flux is essentially constant if the stator is connected to the infinite bus. Thus we have a natural decoupling between the stator flux and the rotor current. Therefore the stator flux solely depends on the stator voltage while the rotor current would depend on both the stator and the rotor voltage. In order to achieve feedback linearization and decoupling, a state feedback matrix will have to be determined. Since the state variables are observable a state feedback should be possible. In a doubly-fed induction machine drive the control is excercized on the rotor side. The stator voltage and frequency is constant. Hence we will redefine the control vector as

$$
u=\left[\begin{array}{c}
u_{\mathrm{r}} \\
0
\end{array}\right]-k\left[\begin{array}{c}
i_{\mathrm{r}} \\
\psi_{\mathrm{s}}
\end{array}\right]+p\left[\begin{array}{c}
0 \\
u_{\mathrm{s}}
\end{array}\right]
$$

The rotor voltage is used to control the rotor current. In order to obtain a state feedback control we need to determine the feedback gain. As opposed to the conventional approach of transfroming the system into controllable form and obtaining the gain matrix based on pole placement formulae we will take an intuitive approach. To this end we take help of the complex signal flow graph of the machine shown in Fig.1. The rotor current is influenced by the angular velocity physical feedback which is the consequence of the relative motion of the winding and the reference frame. In addition the stator flux induces an opposing voltage due to the coupling in the magnetic circuit. In order to simplify the system structure we will use state feedback to compensate the physical feedback. If we look at the system matrix given in (4), we would like to cancel the physical feedback due to stator flux and to compensate for cross coupling due to the observer frame. Since the stator is connected to a constant voltage bus, we will also compensate for the forward coupling between the rotor current and the stator flux through the mutual inductance, Fig.1. Since we know that the resultant system matrix is given as

$$
\hat{\boldsymbol{A}}=(\boldsymbol{A}-\boldsymbol{B} k)
$$

and we would like to have a resultant system matrix as

$$
\hat{\boldsymbol{A}}=\left[\begin{array}{lr}
-\frac{1}{\tau_{\mathrm{r}}^{\prime}}+\frac{k_{z} l_{\mathrm{b}}}{\sigma l_{\mathrm{r}} \tau_{\mathrm{s}}} & 0 \\
0 & -\frac{1}{\tau_{\mathrm{o}}}-j\left(\omega_{\mathrm{s}}-\omega\right)
\end{array}\right]
$$

it is possible to determine the feedback gain matrix by solving (9) by substituting (10) and (6). Hence the feedback gain matrix for the required system will be

$$
k=\left[\begin{array}{lr}
-j\left(\omega_{\mathrm{s}}-\omega\right) \sigma l_{\mathrm{r}} & \frac{k_{\mathrm{s}}}{\tau_{\mathrm{s}}} \\
\frac{l_{\mathrm{h}}}{\tau_{\mathrm{s}}} & -j \omega
\end{array}\right]
$$

The state feedback matrix now cancels the physical state feedback. In the system at hand the constant voltage can be likened to a disturbance. This will be compensated by choosing an appropriate gain matrix in (8) such that the influence of stator voltage is negated. This gives us the feedforward gain matrix

$$
\boldsymbol{p}=\left[\begin{array}{rr}
0 & k_{\mathrm{s}} \\
0 & 0
\end{array}\right]
$$

With the above state feedback and feedforward gain the resultant electromagnetic system of a doublyfed induction machine is shown in Fig. 3. The state-space equation for the resultant system is given by

$$
\dot{x}=(A-B k) x+B\left[\begin{array}{c}
u_{\mathrm{r}} \\
0
\end{array}\right]
$$

The pole plot for this system is given in Fig.4. A current control will now be implemented on the resultant system. 


\section{STATE FEEDBACK ROTOR CURRENT CURRENT CONTROL}

The pole plot of the electromagnetic system of the uncompensated induction machine shows that the system of second order. In addition it is nonlinear. In order to control the active and reactive power in the machine a decoupled current control is required. To this end the stator flux vector control was proposed [2]. The simplified first order model presented by Leonhard is possible if a fast current control is implemented. We will see how a rotor current control is designed in a compensated system. By using state feedback we have decoupled the system. Since the stator flux is independent of the rotor current and in addition the stator flux feedback is compensated, we have a simplified structure for rotor current control. To this end we propose to use a control structure shown in Fig. 5 where

$$
y^{*}=\left[\begin{array}{c}
i_{\mathrm{r}}^{*} \\
0
\end{array}\right]
$$

and

$$
\begin{aligned}
y & =\boldsymbol{C x} \\
y & =\left[\begin{array}{ll}
1 & 0 \\
0 & 0
\end{array}\right]\left[\begin{array}{c}
i_{r} \\
\psi_{\mathrm{s}}
\end{array}\right]
\end{aligned}
$$

To design the controller we need to ascertain the controller matrix, $\boldsymbol{G}$.

From Fig.5 we note that the closed loop system matrix is

$$
\boldsymbol{A}_{\mathrm{cl}}=(\boldsymbol{A}-\boldsymbol{B} \boldsymbol{k}-\boldsymbol{B} \boldsymbol{G C})
$$

From (10) and (17) we can define a SISO tranfer function for the rotor current control as

$$
\frac{I_{\mathrm{r}}(s)}{I_{\mathrm{r}}^{*}(s)}=\frac{\left(\frac{g_{11}}{\sigma l_{\mathrm{r}}}-\frac{k_{\mathrm{s}} g_{21}}{\sigma l_{\mathrm{r}}}\right)}{\left(s+\frac{1}{\tau_{\mathrm{r}}^{\prime}}-\frac{k_{s} l_{\mathrm{h}}}{\sigma l_{\mathrm{r}} \tau_{\mathrm{s}}}+\frac{g_{11}}{\sigma l_{r}}\right)}
$$

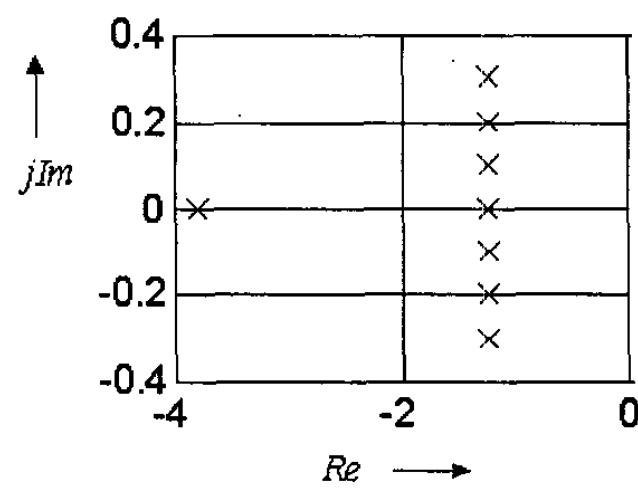

Fig. 4. Pole Plot with state feedback control

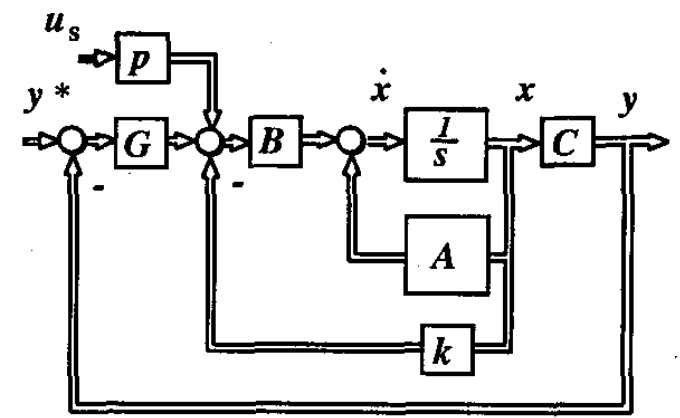

Fig. 5. State feedback control system

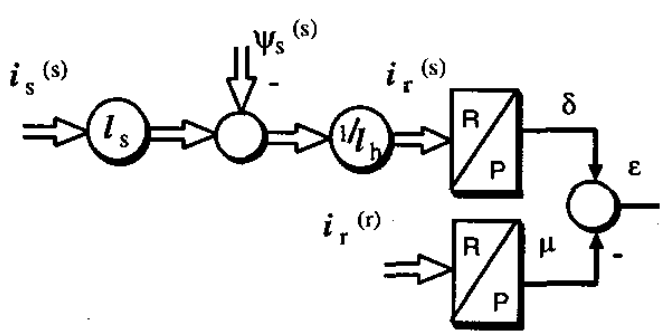

Fig. 6. Speed estimation.

where $g_{11}$ and $g_{21}$ are elements of the control matrix In order to achieve zero steady-state error the following condition should be satisfied

$$
g_{21}=-\frac{\sigma l_{\mathrm{r}}}{k_{\mathrm{s}}}\left(\frac{1}{\tau_{\mathrm{r}}^{\prime}}-\frac{k_{\mathrm{s}} l_{\mathrm{h}}}{\sigma l_{\mathrm{r}} \tau_{\mathrm{s}}}\right)
$$

The resultant controller matrix is given as

$$
\boldsymbol{G}=\left[\begin{array}{ll}
g_{11} & 0 \\
-\frac{\sigma l_{s}}{k_{\mathrm{s}}}\left(\frac{1}{\tau_{\mathrm{r}}^{\prime}}-\frac{k_{s} l_{h}}{\sigma l_{\mathrm{r}} \tau_{0}}\right) & 0
\end{array}\right]
$$

\section{IMPLEMENTATION OF THE CONTROL}

The rotor current vector control is implemented as shown in Fig. 7. The block $\mathrm{S}$ in this figure is the speed estimator as shown in Fig. 6. The quantities measured are the stator current and voltage and the rotor current. It should be noted that the rotor currents are measured in rotor coordinate system and hence have to be transformed into the stator field coordinate system. The stator field is estimated as

$$
\psi_{\mathrm{s}}=\int u_{\mathrm{s}}-i_{\mathrm{s}} r_{\mathrm{s}}
$$

In order to transform the rotor current we require the rotor position. Fig. 6 describes the method for rotor position estimation. Thus both the stator flux and the rotor current are made available in field coordinates. The rotor current control is implemented in the stator field coordinate system. 


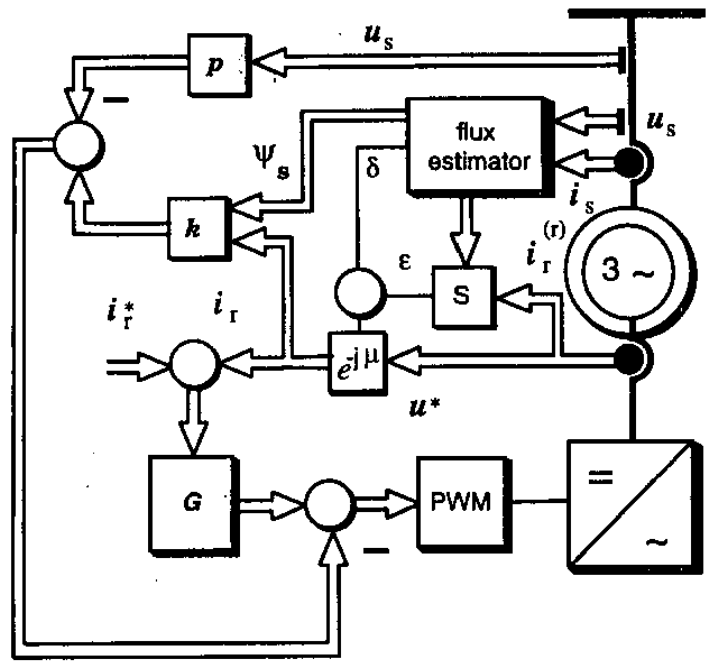

Fig. 7. Rotor Current Control in doubly fed machine.

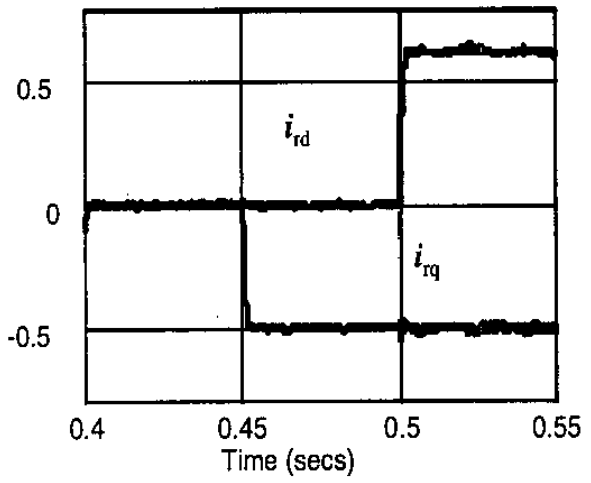

Fig. 8. Rotor Current Control in doubly fed machinesimulation result.

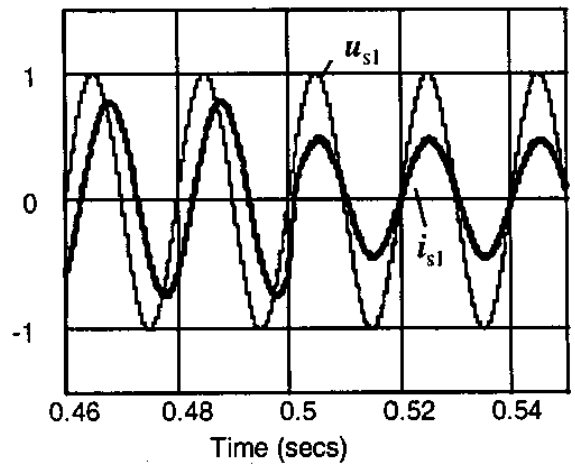

Fig. 9. The stator phase voltage and the stator phase current for the above condition.

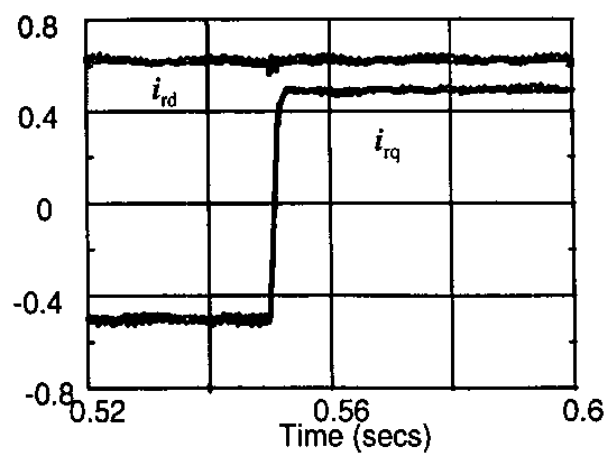

Fig. 10. Rotor Current Control in doubly fed machinesimulation result: motoring to generation at unity power factor.

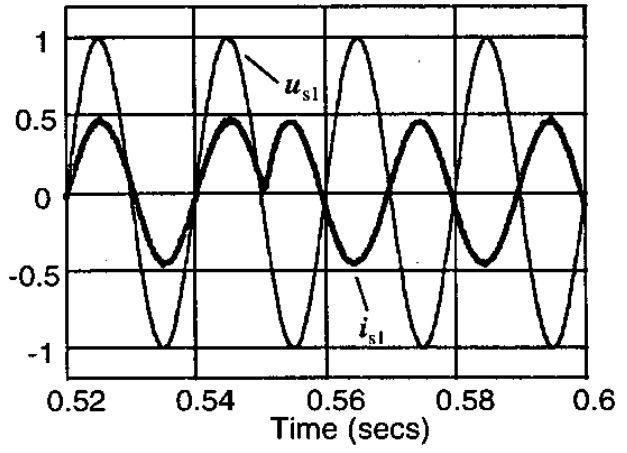

Fig. 11. Stator phase voltage and stator phase current for the above condition: motoring to generation at unity power factor.

Earlier publications [3] and [4] have used PI-type controllers. However as we can see that due to the varying pole positions we cannot use standard design procedure for PI-controllers. Leonhard [2] uses compensation terms alongwith the PI-controller for rotor current control. However the compensation terms only account for the back-emf and the cross coupling terms. As opposed to that, the proposed method shows how a state feedback using the complex signal flow graph helps to simplify the control structure and design a simple control. The simulation result of such a controller is shown in Fig. 8. The controller is a proportional type and obtained by selecting the Gain mtrix as $g_{11}=\tau_{\mathrm{e}}$ where $\tau_{\mathrm{e}}$ is the desired time constant, $(0.5 \mathrm{~ms}$ in Figs. 8 and 10). The term $g_{21}$ as per (19) compensates for the ir-drop in the rotor winding. The proportional gain is sufficient when the parameters of the controller match with that of the system. Fig. 8 shows the 
rotor current in the field coordinates. Both active and reactive power is changed. The corresponding change in stator current is shown in Fig.9. The time scale is same but the unity power factor control is shown in greater detail in Fig.9. Unity power factor transition from motoring to generation shows the four quadrant capability which can be used in the non-self starting wind turbines like the vertical axis type. Fig.10 shows the rotor current components and Fig.11 shows the corresponding stator phase voltage and phase current. In case of param-
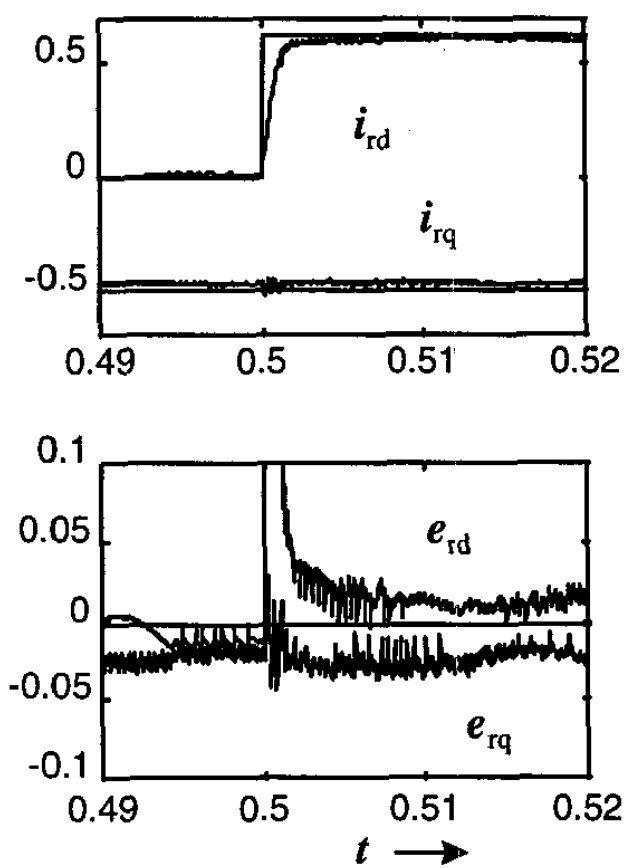

Fig. 12. State feedback with proportional control under inadequate state feedback cancelation.

eter mismatch a steady-state error will be present. This is shown in Fig. 12 where there is $10 \%$ variation in the compensation terms of the feedback gain matrix. The current error is shown in greater detail. We see that both decoupling as well as steady-state error exits in both components. In order to obtain a zero steady-state error we intoduce an intergral control. The feedback and feedforward gain matrices have the same structure as before only that the controller now includes a I part too. The simulation result with a PI-type state feedback control is shown in Fig. 13. The proposed controller has a simple structure and is easy to design as opposed to the state variable controller proposed in [5].

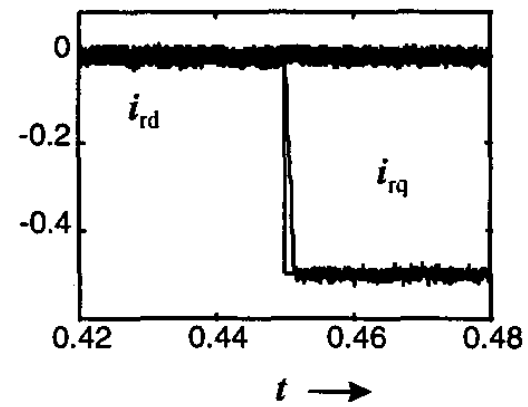

Fig. 13. Rotor current control with PI control and state feedback.

\section{CONClusion}

A model of the doubly fed induction machine is derived using the complex signal flow graph. It can be shown that the structure of the doubly fed induction machine is analogous to the stator fed cage induction machine but for the additional voltage input. The prerequisite for stator flux field orientation is highlighted by the nature of the system. It is seen that the use of complex signal flow graphs leads to a simpler design strategy. Understanding that in doubly fed induction machine drive rotor current control is the sole means of achieving the desired active and reactive power relation, we have used state variable feedback to simplify the system structure. A feedforward compensation of the stator voltage completes the decoupling. A simple proportional control matrix satisfies the requirement. However to achieve zero steady-state error under parameter mismatch condition we use an integral control in addition. The simulation results of the scheme are shown to verify the control struture.

\section{REFERENCES}

[1] J. Holtz, "The representation of ac machine dynamics by complex signal flow graphs," IEEE Transactions on Industrial Electronics, vol. 42, no. 3, pp. 263-271, 1995.

[2] W. Leonhard, Control of Electrical Drives, Springer Verlag, Berlin, 1986.

[3] R. Pena, J. C. Clare, and G. M. Asher, "Doubly fed induction generator using back-to-back pwm converters and its application to variable-speed wind-energy generation," IEE Proc. Electr. Power Appl., vol. 143, no. 3 pp. 231-241, 1996.

[4] W. Cheng and Longya $X_{u}$, "Torque and reactive power control of a doubly-fed induction machine by position sensorless scheme," in IEEE IAS Annual Meeting, 1994, pp. $496-502$.

[5] D. C. Lee, S. K. Sul, and M. H. Park, "High performance current regulators for a field-oriented controlled induction motor drive," IEEE Transactions on Industry Applications, vol. 30, no. 4, pp. 1039-1047, 1994. 